\title{
Proficiency Testing Challenge
}

National Cancer Institute

\section{Source}

National Cancer Institute. Proficiency Testing Challenge. NCI Thesaurus. Code C99490.

Any individual test given to a laboratory as part of a proficiency test. 